\title{
Quasi-Solid State Electrolytes Based on Nonionic Surfactant-PEGDME Composites for Dye-Sensitized Solar Cells
}

\author{
Hyosung An, Hyo-young Park, Eun-Mi Kang, Dae Won Cho, Chan Woo Lee, ${ }^{\dagger}$ and Jong-Man Kim* \\ Department of Chemical Engineering, Hanyang University, Seoul 133-791, Korea.*E-mail: jmk@hanyang.ac.kr \\ †Department of Chemistry, Hanyang University, Seoul 133-791, Korea \\ Received August 18, 2011, Accepted August 25, 2011
}

Key Words : Dye-sensitized solar cell, Oligomer, Electrolyte, Brij 72

Dye-sensitized solar cells (DSSCs) based on $\mathrm{TiO}_{2}$ as the nanostructured electrode have achieved an impressive photo-to-energy conversion efficiency $(\sim 11 \%$ at 1 sun, AM 1.5) where the electrolyte is organic solvent containing $\mathrm{I}^{-} / \mathrm{I}_{3}{ }^{-}$ as redox couple. ${ }^{1,2}$ However, the presence of liquid electrolytes in the DSSC often requires robust sealing and longterm stability due to the volatility of organic solvent has been considered as a practical limitation. Therefore, many studies have been investigated to overcome the drawbacks of the liquid electrolyte system by replacing the liquid electrolyte with solid or quasi-solid state electrolytes, such as $p$-type semiconductor, ${ }^{3}$ hole transporting organic materials, ${ }^{4}$ ionic liquids, ${ }^{5}$ solid polymer electrolytes (SPEs), ${ }^{6}$ and gel electrolytes. ${ }^{7}$

In particular, SPEs have many advantages such as the low production cost, good mechanical strength and long term stability. For example, polyethylene oxide (PEO) as a solvent for SPEs has been most extensively studied owing to its chemical stability and high solvating ability of salts. ${ }^{8}$ However, PEO's poor ionic conductivity arising from high crystallinity has been a disadvantage for the application of DSSCs. Several studies are being attempted to improve its poor conductivities by using oligomer approach, ${ }^{9}$ PVDFHFP based gel polymer electrolytes (GPEs), ${ }^{10}$ and modified nano-clay. ${ }^{11}$

We have investigated quasi-solid state electrolytes for DSSCs based on PEO and nonionic surfactant Brij 72 (Figure 1), which is one of the known surfactants that can solidify the electrolyte. Unlike simple polymers, small molecule, Brij 72 is expected to allow penetration of electrolyte molecules into the pores of mesoporous $\mathrm{TiO}_{2}$ film on the surface of working electrode. In addition, this quasi-solid state electrolyte is expected to solve the problems related to the sealing and evaporation of liquid at high working temperature.

Four quasi-solid state electrolyte solutions were prepared with PEGDME oligomer and Brij 72 at different weight ratios (e.q., 100:0 (0 wt \%), 95:5 (5 wt \%), 90:10 (10 wt \%) and 85:15 (15 wt \%)). Prepared solutions were mixed with a

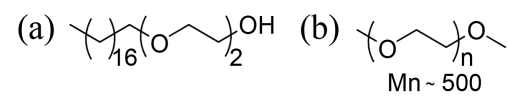

Figure 1. Chemical structures of (a) $\mathrm{Brij}^{\circledR} 72$ and (b) PEGDME. redox couple consisting of 1-methyl-3-propylimidazolium iodide (MPII) and $\mathrm{I}_{2}$ at 10:1 molar ratio respectively. Figure 2 shows that the electrolyte solution (Figure 2(b)) changes to a quasi-solid state (Figure 2(a)) when surfactant, Brij 72 is added at room temperature.

Blocking layers were prepared by spin-coating of 1butanol solution containing titanium(IV)iso (ethylacetoacetato)diisopropoxide on a FTO glass (Pilkington, $\sim 8 \Omega /$ $\mathrm{cm}^{2}$ ), followed by annealing at $450{ }^{\circ} \mathrm{C}$ in the air for $30 \mathrm{~min}$. Two kinds of $\mathrm{TiO}_{2}$ pastes (DSL 18NR-T, particle size $20 \mathrm{~nm}$ and WER2-O reflector, particle size $200 \mathrm{~nm}$, obtained from Dyesol Ltd.) were deposited on above substrates by the layer-by-layer deposition using doctor-blade technique, followed by calcination process at $450{ }^{\circ} \mathrm{C}$ in the air for 30 min. After cooling to $80{ }^{\circ} \mathrm{C}$, the prepared $\mathrm{TiO}_{2}$ electrodes were immersed into $0.3 \mathrm{mM}$ solution of the $\mathrm{RuL}_{2}(\mathrm{NCS})_{2}: 2$ TBA ( $\mathrm{L}=2,2^{\prime}$-bipyridyl-4,4'-dicarboxylic acid; TBA = tetrabutylammonium) in ACN:tert-BuOH $(1: 1 \mathrm{v} / \mathrm{v})$ at $30^{\circ} \mathrm{C}$ for $24 \mathrm{~h}$ (Ruthenium sensitizer is known as N719). To prepare the Pt counter electrode, $5 \mathrm{mM}$ dihydrogen hexachloroplatinate (IV) solution, (e.q., Pt 20\%) in isopropanol was dropped onto the FTO glass substrate and then spincoated at $1000 \mathrm{rpm}$, followed by annealing at $450{ }^{\circ} \mathrm{C}$ for 30 min. An open sandwich-type film cell was fabricated in the air by clamping between working electrode and Pt counter electrode at $60^{\circ} \mathrm{C}$, in which electrolytes was present inside.

Figure 3 shows the photocurrent-voltage profile of the DSSCs depending upon concentration of Brij 72 electrolyte measured under 1 sun condition (AM $1.5 \mathrm{G}, 100 \mathrm{~mW} / \mathrm{cm}^{2}$ ). The results show that as concentration of Brij 72 was raised, photocurrent density increases and voltage of the cell decreases. More interesting observation is that the dark current is inversely dependent on the concentration of Brij (a)

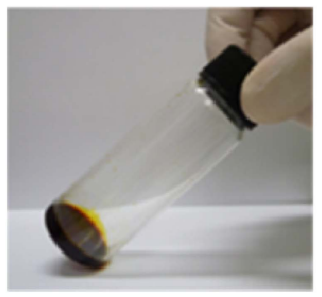

(b)

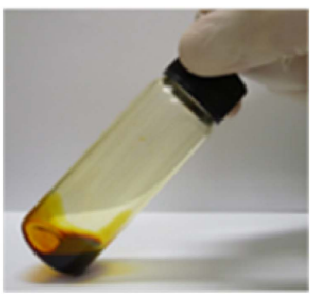

Figure 2. Phase condition of (a) PEGDME with Brij 72 and (b) PEGDME without Brij 72. 


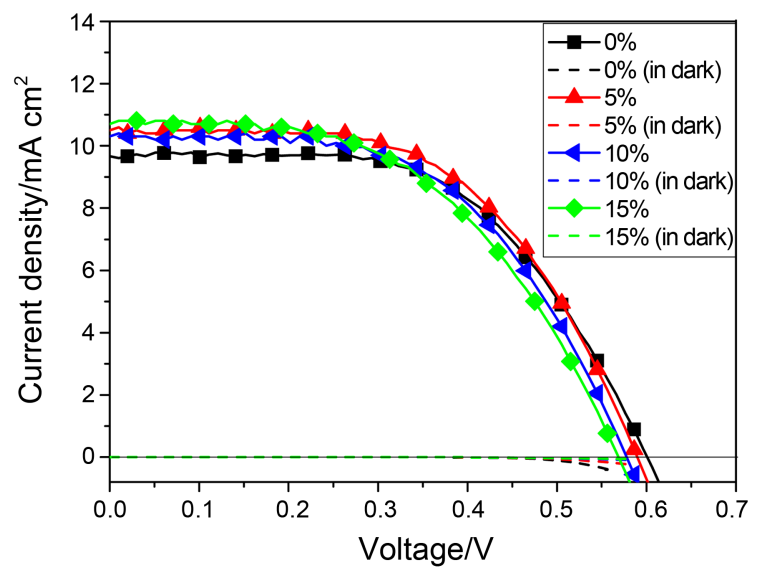

Figure 3. $J-V$ curves of the DSSCs fabricated with amphiphilic electrolyte (Brij 72) and PEGDME electrolyte under AM 1.5 (100 $\mathrm{mW} / \mathrm{cm}^{2}$ ) and in dark : $0 \mathrm{wt} \%$ (square), $5 \mathrm{wt} \%$ (round), $10 \mathrm{wt} \%$ (left triangle) and $15 \mathrm{wt} \%$ Brij 72 (diamond) in the electrolytes.

72. These behaviors are presumably due to the result of the decrease in the concentration of $\mathrm{I}_{3}^{-}$near the $\mathrm{TiO}_{2}$ surface arising from amphiphilic Brij 72, that is, hydroxyl moiety of that is directed toward $\mathrm{TiO}_{2}$ and alkyl chain moiety toward electrolyte side.

The photovoltaic properties and ionic conductivity as a function of concentration of Brij 72 are listed in Table 1. The results show that conductivity patterns were dramatically decreased even when small amount of Brij 72 was present. However, $J_{\mathrm{SC}}$ was slightly increased regardless of ionic conductivity due to the blocking of recombination arising by amphiphilic Brij 72 near the surface of dyed $\mathrm{TiO}_{2}$. In addition, as opposed to the $V_{O C}$ and fill factor $(F F), J_{S C}$ showed a maximum at $5 \mathrm{wt} \%$ Brij 72 content, resulting in maximum energy conversion efficiency $(3.46 \%)$ at the condition of 100 $\mathrm{mW} / \mathrm{cm}^{2}, 5 \mathrm{wt} \%$ of Brij72, and MPII $+\mathrm{I}_{2}$.

The influences of the concentration of Brij72 in the amphiphilic electrolyte were explored by using interfacial resistance-characteristics of DSSCs via EIS measurements. Figure 4 shows the Nyquist plots of quasi-solid state DSSCs depending upon the concentration of Brij 72 at $100 \mathrm{~mW} / \mathrm{cm}^{2}$ illumination. The charge transfer resistance at the interface of Pt surface and the electrolyte of DSSCs, $\mathrm{R}_{\mathrm{ct} 1}$, were almost the same regardless of any concentration of Brij 72. However, the charge resistance at the interface of dyed $\mathrm{TiO}_{2}$ film and the electrolyte, $\mathrm{R}_{\mathrm{ct} 2}$, varied considerably owing to different resistance in the amphiphilic composite electrolytes. The smallest $\mathrm{R}_{\mathrm{ct} 2}$ of the DSSCs was observed when $5 \mathrm{wt} \%$ Brij

Table 1. Photoelectrochemical data of the DSSCs fabricated by varying Brij 72 concentration in the amphiphilic composite electrolytes and ionic conductivity of the electrolytes

\begin{tabular}{cccccc}
\hline $\begin{array}{c}\text { Brij 72 } \\
\text { content }\end{array}$ & $\begin{array}{c}J_{\text {SC }} \\
\left(\mathrm{mA} \mathrm{cm}^{-2}\right)\end{array}$ & $\begin{array}{c}V_{\mathrm{OC}} \\
(\mathrm{mV})\end{array}$ & $\begin{array}{c}\eta \\
(\%)\end{array}$ & $\begin{array}{c}F F \\
(\%)\end{array}$ & $\begin{array}{c}\sigma \\
\left(10^{-5} \mathrm{~S} \mathrm{~cm}^{-1}\right)\end{array}$ \\
\hline 0 wt \% & 9.56 & 600 & 3.37 & 58.8 & 6.62 \\
5 wt \% & 10.56 & 593 & 3.46 & 55.2 & 0.49 \\
10 wt \% & 9.95 & 587 & 3.27 & 54.3 & 0.31 \\
15 wt \% & 10.21 & 592 & 3.18 & 52.5 & 0.26 \\
\hline
\end{tabular}

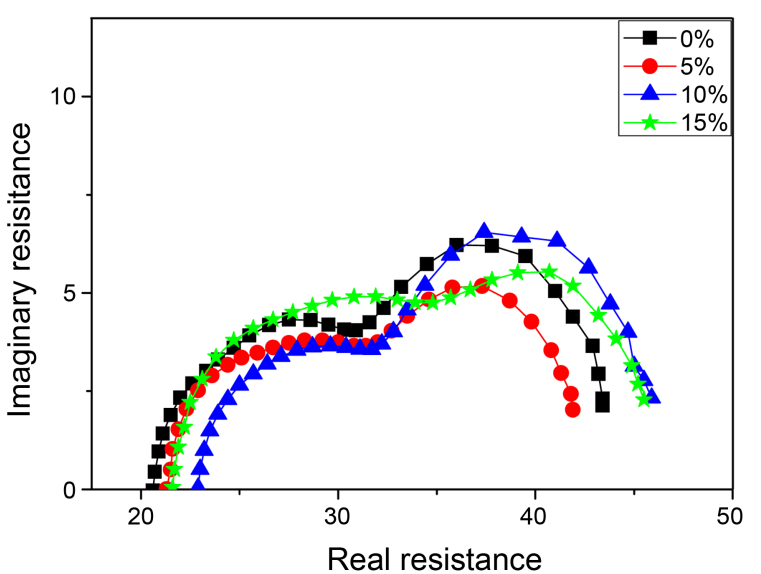

Figure 4. Electrochemical impedance spectra for quasi-solid state DSSCs using amphiphilic composite electrolytes: $0 \mathrm{wt} \%$ Brij 72 (square), 5 wt \% Brij 72 (round), $10 \mathrm{wt} \%$ Brij 72 (triangle) and 15 wt \% Brij 72 (star) in the electrolytes.

72 was used.

In conclusion, the effects of the usage of Brij 72 in the electrolyte on the photovoltaic properties of DSSCs were investigated. Even though increment of the concentration of Brij 72 in electrolytes brought about decrease in fill factor, ionic conductivity and photovoltage, surface recombination and interfacial resistance were fallen down. In addition, when over 5 wt $\%$ of Brij 72 and MPII $+\mathrm{I}_{2}$ were used together, the electrolytes turned into quasi-solid state even at room temperature and the DSSC at the condition of $5 \mathrm{wt} \%$ of Brij 72 exhibited smallest charge transfer resistance and dark current, resulting in higher energy conversion efficiency $(3.42 \%)$ at $100 \mathrm{~mW} / \mathrm{cm}^{2}$ illumination.

Acknowlegments. The authors gratefully thank National Research Foundation of Korea for financial support through Center for Next Generation Dye-sensitized Solar Cells (20110001057), Basic Science Research Program (20110018602).

\section{References and Notes}

1. O’Regan, B.; Grätzel, M. Nature 1991, 353, 737.

2. Wang, P.; Zakeeruddin, S. M.; Moser, J. E.; Humphry-Baker, R.; Comte, P.; Aranyos, V.; Hagfeldt, A.; Nazeeruddin, M. K.; Grätzel, M. Adv. Mater. 2004, 16, 1806.

3. Kumara, G. R.; Kaneko, S.; Okuya, M.; Tennkone, K. Langmuir 2002, 18, 10493.

4. Bach, U.; Lupo, D.; Comte, P. Nature 1998, 395, 583.

5. Kubo, W.; Kiramura, T.; Hanabusa, K.; Wada, Y.; Yanagida, S. Chem. Commun. 2002, 374.

6. Nogueira, A. F.; Durrant J. R.; De Paoli, M.-A. Adv. Mater. 2001, 13,826 .

7. Stathatos, E.; Lianos, P.; Zakeeruddin, S. M.; Kiska, P.; Grätzel, M. Chem. Mater. 2003, 15, 1825.

8. Mao, G.; Perea, R. F.; Howells, W. S.; Price, D. L.; Saboungi, M. L. Nature 2000, 405, 163.

9. Kang, M.-S.; Kim, J. H.; Won, J. O.; Kang, Y. S. J. Phys. Chem. C 2007, 111, 5222.

10. Suryanarayanana, V.; Lee, K. M.; Ho, W. H.; Chen, H. C.; Ho, K. C. Sol. Energy Mater. Sol. Cells 2007, 91, 1467.

11. Tsui, M.-C.; Tung, Y.-L.; Tsai, S.-Y., Lan, C.-W. J. Sol. Energy Eng. 2011, 133, 1. 